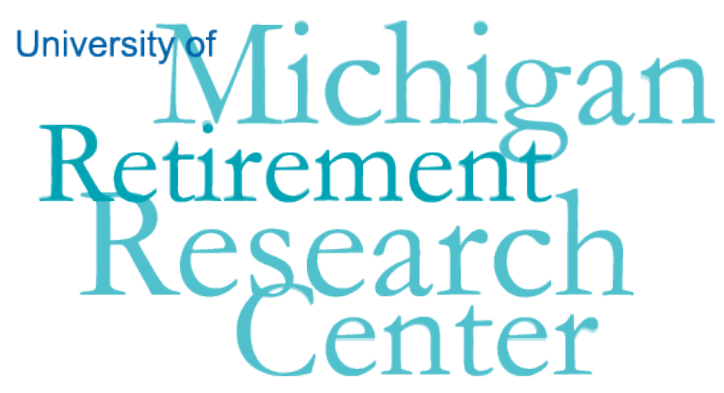

Working Paper

WP 2012-264

\title{
Communication with Individuals with Intellectual Disabilities and Psychiatric Disabilities: A Summary of the Literature
}

Walton O. Schalick III, Cecelia Westbrook and Brittany Young

\begin{tabular}{|l|l|}
\hline $\mathrm{M}$ & $\mathrm{R}$ \\
\hline $\mathrm{R}$ & $\mathrm{C}$ \\
\hline
\end{tabular}

Project \#: UM12-Q1 



\title{
Communication with Individuals with Intellectual Disabilities and Psychiatric Disabilities: A Summary of the Literature
}

\author{
Walton O. Schalick III, MD, PhD \\ University of Wisconsin and \\ Central Wisconsin Center for the Developmentally Disabled \\ Cecelia Westbrook, MD \\ University of Wisconsin \\ Brittany Young, MD \\ University of Wisconsin
}

August 2012

\author{
Michigan Retirement Research Center \\ University of Michigan \\ P.O. Box 1248 \\ Ann Arbor, MI 48104 \\ http://www.mrrc.isr.umich.edu
}

(734) 615-0422

\section{Acknowledgements}

This work was supported by a grant from the Social Security Administration through the Michigan Retirement Research Center (Grant \# 5 RRC08098401-04-00). The findings and conclusions expressed are solely those of the author and do not represent the views of the Social Security Administration, any agency of the Federal government, or the Michigan Retirement Research Center. 


\title{
Communication with Individuals with Intellectual Disabilities and Psychiatric Disabilities: A Summary of the Literature
}

\begin{abstract}
Governmental agencies serve individuals with Intellectual Disabilities (ID) and Psychiatric Disabilities (PD) and must consequently communicate with these individuals at multiple points, from interviews with claims representatives to written notices sent to applicants and beneficiaries about highly complex material. We review the social scientific, survey research-based, cognitive testing-based and other relevant literatures regarding effective communication with these individuals. Given the nature of governmental contact with individuals with ID and PD, particular interest falls upon formal written communication, but other modes of communicating factual information (e.g., telephone, in-person) are also within the scope of this literature review. We evaluate what is known regarding the receptive and expressive communicative capacities of these individuals. We attempt to evaluate what is known about the communicative strategies to determine how the literature may inform a set of evidence-based best practices regarding for effective and efficient communication with individuals with ID and PD.
\end{abstract}




\section{GENERAL REMIT:}

Communication is an integral part of the human experience in which most individuals engage daily. The American Speech-Language Hearing Association (ASHA) defines communication as, "any act by which one person gives or receives from another person information about that person's needs, desires, perceptions, knowledge, or affective states." The ASHA guidelines further specify that communication can be, "intentional or unintentional, may involve conventional or unconventional signals, may take linguistic or nonlinguistic forms, and may occur through spoken or other modes" (ASHA, 1992). Thus, communication plays a critical role in both personal day-to-day interactions as well as in more formal situations between individuals and representatives of an establishment.

Two groups that may experience difficulties with communication are: a) those with cognitive, developmental, or intellectual disabilities (ID), for example those with autism, "mental retardation," or cerebral palsy and b) those with psychiatric disabilities (PD), for example those with depression, schizophrenia, or bipolar disorder. These populations have a wide range of cognitive, expressive and receptive capacities. The Social Security Administration (SSA) and other federal agencies serve individuals in both of these groups.

Governmental agencies must consequently communicate with these individuals at multiple points, from interviews with claims representatives to written notices sent to applicants and beneficiaries about highly complex material. Thus information in the social scientific, survey research-based, cognitive testingbased and other relevant literatures about how to communicate effectively with these individuals can be useful at a practical level to governmental service providers.

Given the nature of governmental contact with individuals with ID/PD, particular interest falls upon formal written communication, but other modes of communicating factual information (e.g. telephone, in-person) are also within the scope of this literature review. A focus has been on whether there is research regarding the ability to test comprehension of written materials by individuals with ID/PD that might inform governmental efforts.

Consequently, the scope of the following review includes a wide sweep of mechanisms of communication with individuals with ID/PD with the express intent of offering further insights for those in government who interact with such individuals. 


\section{METHODOLOGY}

Phase 1: of this project prepared for the review utilizing the basic framework of a Systematic Review (in this endeavor features of a Meta-Analysis would have been valuable, but, given the qualitative nature of much of the available research literature, a pure meta-analysis would have been both complex and ultimately unrepresentative of the material). This phase followed established protocols:

1. Formulation of the problem

2. Preparation for search of literature

3. Establishment of selection criteria of studies

Phase 2: During the analytic phase of this project, had it been a clinical review, meta-analytic prioritization might have been useful (e.g. the Jadad criteria). ${ }^{1}$ In the circumstance of ID/PD communication literature, however, there is a significant degree of heterogeneity, conflict and methodological/paradigmatic variation, not the least because of the significant variation in the populations considered. Consequently, a meta-narrative methodology was found to be more valuable.

Following this approach, we did not hand-search journals and we placed somewhat less emphasis than usual on simple database searches, favoring the meta-narrative stress of hierarchical source generation, and thence a snowballing technique (searching references of references and using citation-tracking databases). ${ }^{2}$ To help manage the data, sources were indexed on a reference manager database according to four criteria: how we identified them, research tradition, relevance to our review (high, medium, low), and study design.

We identified seminal sources in each meta-narrative by asking what were cited as key original and scholarly contributions by other researchers in the same

${ }^{1}$ Jadad, A.R.; Moore R.A., Carroll D., Jenkinson C., Reynolds D.J.M., Gavaghan D.J., McQuay H.J. (1996). "Assessing the quality of reports of randomized clinical trials: Is blinding necessary?" Controlled Clinical Trials. 1996; 17: 1-12; Jadad A.R.; Enkin M.

Randomized Controlled Trials: Questions, Answers and Musings (2nd ed.). Oxford: Blackwell, 2007.

${ }^{2}$ Some criticism of the snowballing technique, especially in group interview research, exists (e.g., Biernacki, P. and Waldorf, D., "Snowball Sampling: Problems and Techniques of Chain Referral Sampling," Sociological Methods \& Research 1981; 10: 141-63), however, given the breadth of possible fields/methodologies that border on the current subject, this approach offered the greatest promise for efficient return in the project. 
tradition. From this collection of material, we read the primary sources and used narratives to summarize their key methods and findings. With these sources, we extracted the concepts, theories, and preferred methods that formed the criteria for rigor in each meta-narrative, and used these to guide our appraisal of empirical studies. We gave greater weight to studies that had been flagged as "high quality" by other scholars in a tradition, but because the literature includes a wide range of different paradigms, perspectives, and study designs, we did not use a formal qualitative scoring system. Moreover, given the growth of new technologies in communication, slightly greater weight was given to more recent publications in order to encourage a slight bias towards approaches that may (or may not) prove to be cutting edge for government agencies.

The following meta-narrativistic foci led the analysis of the resulting narratives in phase 2:

1. We identified what bodies of knowledge and specific research traditions are relevant to the understanding of IDCommunication/PDCommunication.

2. In each of these traditions we assessed,

a. What are the key concepts (including assumptions about the nature of the problem), theories, and methodological approaches?

b. What are the seminal theoretical works and high quality empirical studies?

c. What are the key empirical findings, and what has been concluded from them?

3. When comparing across the different traditions we assessed,

a. To what extent were the assumptions, approaches, findings, and conclusions of the different traditions commensurable?

b. What higher-order insights can be gained from the study of the agreements and disagreements among them?

Phase 3: In the synthesis phase, we compared and contrasted the different metanarratives and exposed tensions and paradoxes, seeking explanations for these in terms of how researchers have conceptualized ID/PD communication and chosen to explore it. ${ }^{3}$ To assure quality of the final product for its targeted consumers, we have had an expert reader, Professor Pamela Herd, read the prefinal version, making suggestions both topical and stylistic, which are to be incorporated into the final version for submission to the funders.

${ }^{3}$ Greenhalgh, T., Robert, G., Macfarlane, F., Bate, P., Kyriakidou, O., and Peacock, R. Storylines of Research in Diffusion of Innovation: A Meta-narrative Approach to Systematic Review. Social Science and Medicine. 2005; 61: 417-30. 
The conclusions herein presented represent the synthetic assessment of the lead author, Professor Schalick, and not necessarily those of the student research associates or the expert reader. In addition, all views herein are those exclusively of the authors, but do not necessarily represent the views of MRRC, the University of Michigan, SSA, or the U.S. Government.

\subsection{Introduction}

Intellectual disability (ID) refers to a wide range of clinical conditions with diverse etiologies, involving a wide range of neural deficits and mental abilities (Pulsifer, 1996; Carlessimo, Marotta, \& Vicari, 1997; Carvajal et al., 2012). In general, ID is a collection of conditions of incomplete or arrested development of the brain and associated structures. Many of these conditions affect communication.

It is estimated that about $3 \%$ of the world's school-aged children have some form of ID (Ouellette-Kuntz, 2005) and that individuals with ID tend to be of lower SES and more likely to be reliant on public services in some way (Havercamp, Scandlin, \& Roth, 2004; Drainoni et al., 2006; Ward, Nichols, \& Freedman, 2010). Given the prevalence of ID in the general population and the frequency with which these individuals are served by federal agencies, it is of interest to these agencies to know how to best communicate with this service population.

In 1988 the NINDS (NIH) estimated that 90\% of children with severe ID manifested some type of language disorder (McLean et al., 1999); likewise adults with mild to moderate ID often exhibit difficulties with speech and language (Cheslock et al., 2008). Research has shown that adults with ID exhibit deficits in multiple aspects of communication, including written, expressive, and receptive modes (Berry, 1972; Merrill \& Mar, 1987; Abbeduto, Furman, \& Davies, 1989; Abbeduto \& Nuccio, 1991; Merrill \& Jackson, 1992a; Merrill \& Jackson, 1992b; Belva et al., 2012). This may be due to the fact that individuals with ID have reduced cognitive resources compared to typical peers (Kail, 1992; Koul \& Clapsaddle, 2006). One may similarly argue that environmental deficits do not optimize what communication is possible.

In areas such as health care, individuals with ID often face cognitive challenges in communicating their needs, understanding and adherance to recommendations or treatments (Ward, Nichols, \& Freedman, 2010). Given the communicative challenges faced by individuals with ID, it stands to reason that the most effective ways to communicate with these people may be different from 
the ways in which information is routinely communicated with persons who do not have ID.

The purpose of this portion of the review is to examine the current literature on communication with adults with ID. We will attempt to evaluate what is known regarding the receptive and expressive communicative capacities of these individuals and with an aim to determine how the literature may inform a set of evidence-based best practices regarding how to most effectively and efficiently communicate with individuals with ID.

\subsection{Specific Methods}

As previously noted, there is a significant degree of heterogeneity, conflict and methodological/ paradigmatic variation among the available ID literature. Consequently, a meta-narrative methodology was deemed to be more valuable than a more traditional meta-analytic prioritization approach.

Literature searches for this portion of the project relied mainly on the PubMed by the National Institutes of Health and SocINDEX by EBSCO Publishing databases. Initial searches included terms such as "adults," "intellectual disability," "communication," "mental retardation," "receptive," "expressive," and "language." In this process, key papers were identified and a snowballing technique (searching references of references and using citation-tracking databases) was used as a means of hierarchical source generation in gathering the most relevant literature.

We identified key sources by asking what were cited as key original and scholarly contributions by other researchers in the same tradition. From this collection of material, we read the primary sources and have summarized their key findings and used the concepts, theories, and preferred methods therein to guide our appraisal of empirical studies. We gave greater weight to studies that have been flagged as "high quality" by other scholars in a tradition, but because the literature includes a wide range of different paradigms, perspectives, and study designs, we did not use a formal quality scoring system.

References were cataloged using Endnote Web. Access to journal articles, scholarly databases, and citation management was through the library resources of the University of Wisconsin - Madison.

In all, from a much larger sample, 61 key papers were eventually identified, which examined the topics of language development and use, communicative abilities, and preference assessment for individuals with ID among them. 
It is notable that much of the extant, relevant work that may offer insights into communication with individuals with ID is rather heterogeneous in nature, ranging from review papers to small-scale interventional experiments, to descriptive studies in larger cross-sections of the population with ID. Thus, a traditional review and comparison of randomized controlled trials is neither practical nor likely to be very helpful given the lack of large randomized controlled trials in this area and the variety in the studies available.

\subsection{Thematic Results: On Categorizing the Heterogeneity of Communicative Ability in Individuals with ID}

In order to determine the most appropriate interventions and approaches to communication with an individual with ID, it is necessary to understand the degree of communicative impairment that exists for that individual. Recent studies have shown that while a general trend can be observed in which those with more severe ID tend to possess fewer communicative skills (Cascella 2004), there exists significant heterogeneity in the communicative abilities among those with severe ID (Carlesimo, Marotta, \& Vicari, 1997; McLean, Brady, \& McLean, 1996; McLean et al., 1999; van der Meer et al., 2011). In this population, expressive communicative abilities alone can range from no intentional communication in any mode to multi-word spoken utterances (McLean, Brady, \& McLean, 1996; McLean et al., 1999). In contrast, among those with mild ID, some are relatively unimpaired and effectively fall within what may be considered the normal range of communicative function. These individuals have even been included within normative samples of standardized speech-language tests (Cascella 2006).

Thus, while those with the most severe ID are likely to need the greatest amount of external support in achieving functional communication, this generalization alone is insufficient if attempting to most effectively address the communicative needs of this population through the practical implementation of communicative supports.

Yet another complicating factor is the fact that while IQ has historically been used as the main criteria for assessing ID, other factors such as adaptive deficits are more important in determining which individuals are labeled as ID. IQ measurements are also not a particularly useful measure of an individual's communicative capacities, as individuals with the same IQ can vary greatly in verbal fluency (Gallagher, 2002).

In light of the great heterogeneity that exists among these individuals in terms of communicative ability, it has been recognized more recently that a holistic 
functional approach to intellectual disability may be preferable to the traditional classification of mild, moderate, severe, and profound ID in assessing the most appropriate services and interventions in multiple domains, including communication, for individuals with ID (Hollenweger \& Moretti, 2012; Luckasson \& Schalock, 2012).

In particular, when considering communicative ability, it has been suggested that both researchers and program planners must insist on more specific descriptions of the communication abilities of new clients or research participants identified as having severe ID (McLean et al., 1999) rather than relying on their classification of "severe ID" alone.

In this setting educational standards adopted by social scientific and biomedical (human) research requirements may be suggestive. When designing trials involving human subjects, informed consent is frequently necessary. Given the complexity of the study designs, impartial Institutional Review Boards demand simplification of study description to provide the contextual data needed to obtain an informed consent (or dissent). This provokes the question of how much simplification is necessary, namely expectations of "least common denominator" educational capacity (often designated as a Sixth- to Eighth-Grade level) helps communication teams identify language, grammatical and content structures. This paradigm has received consequential criticism. Not the least, one must ponder what it means to create a document of 40 pages at a sixth-grade level, but because of its very length, it is unable to sustain the attention of an adult with a sixth-grade reading level (Hochhauser (2004) and Flory \& Emanuel (2004)). Equally, studies involving those with ID are vigorously scrutinized for mechanisms to obtain informed consent or at least assent. The consequent difficulties often lead to studies of such individuals not being performed.

Nevertheless, an individualized functional approach has been used successfully to devise alternative communication methods to improve information exchange with individuals with locked-in syndrome, another group for whom communication often poses significant challenges (Soderholm, Meinander, \& Alaranta, 2011). Functional assessment research has become an important component in treating challenging behaviors in individuals with ID (Matson et al., 2011a), with inherently communicative functions such as attention, and demands being incorporated into the functional assessment (Matson et al., 2011b). Functional communication training has also exceeded criteria as a wellestablished treatment for addressing problem behavior in children with ID and has been characterized as likely, though not proven, to be efficacious with adults (Kurtz et al., 2011). 
One means of making such an assessment of communicative ability was documented and supported in a study by Iacono et al. (2009). In this study, researchers modified the Triple $C$ (Checklist of Communicative Competencies) originally designed by Bloomberg and West (1999) and showed their revised version to be a reliable means of assessing the communication skills of adults with severe ID - particularly those with severe communication impairments who are pre-symbolic or have only limited symbolic ability. This result was also dependent upon the collaborative efforts of both a support worker familiar to the individual with ID as well as with a speech-language pathologist with prior training in the use of the Triple $C$ as an evaluative tool. This is important, as communicative measures that rely solely on the report of familiar staff tend to overestimate language-comprehension (Purcell, Morris, \& McConkey, 1999), while measures that rely solely on unfamiliar trained professionals may miss information about the client's communication skills that are not readily apparent to the professional (van der Gaag, 1989; Iacono et al., 2009).

Thus, the use of a holistic and function-oriented inventories in assessing the communicative abilities and needs of an individual with ID has already been implemented in other populations and other areas of functional improvement among those with ID. It has been shown as an effective component of these therapies, and the extension of this approach is likely to improve outcomes in communicative domains, particularly when considering the heterogeneous nature of communicative abilities present among individuals with ID.

\subsection{Thematic Results: Receptive Communication in Individuals with ID}

Receptive communication refers to the ability of an individual to understand what is being communicated to them by an external stimulus. There are documented differences in aspects of language comprehension and information processing between individuals with ID and matched typical peers. It has been suggested that at least some of these differences are due to deficits in working memory, attention span, symbolic thought, verbal information, and processing resources (Kail, 1992; Merril \& Jackson 1992a; Koul \& Clapsaddle, 2006).

Despite these deficits in receptive communication when compared to typical peers, research has shown that adults with profound ID tend to have stronger abilities in receptive communication than in expressive or written forms of communication (Belva et al., 2012). Receptive communication is often better than is perceived by the casual or even professional observer, as is born out in extensive clinical experience over 17 years by one of the consultants (Schalick). Receptive communication is important for individuals with ID in that it constitutes the individual's "understanding" of what it being communicated to them. 
Regression analyses have also shown that receptive vocabulary was one of the best predictors of performance on a Social Resolution Task for individuals with ID and that the influence of receptive vocabulary level was much stronger in those with ID than in typical peers (Hippolyte et al., 2010). Therefore, it may be of great importance to assess the degree of receptive communication that is possible for an individual with ID, as it represents both what is likely to be their strongest area of communication as well as an area of communication predictive of abilities in other related domains.

It is equally important to remember that receptive communication skills may be stronger in some contexts than in others for a given individual: Context is important. Some individuals with ID demonstrate an awareness of familiar people, events, and routines, but a formal examination of receptive communication behaviors shows that they cannot be said to necessarily understand all of the communicative acts directed toward them in all contexts. In a research setting, these individuals are shown to comprehend basic repetitive and context-dependent communicative actions (e.g. single-step in-context directions, association of objects with specific daily routines, and responding to one's own name) more often than more abstract or symbolic communications (e.g. identification of photographs of familiar people and common objects in a magazine) (Oetting \& Rice, 1991; Cascella, 2004). This warns against taking the word of a caretaker or close family member who may suggest that an individual with ID "understands everything said to him/her" as generalizable to novel situations or more symbolic messages.

With respect to financial knowledge and services, an example of the variation in comprehension and perceived comprehension by researchers is suggested by Mansfield \& Pinto (2008). Their study examined understanding of basic financial tools like credit cards among individuals with consequential ID. Of an initial sample of 72 individuals, 28 declined to participate and 3 were excluded because they could not identify a picture of a credit card as a credit card. Of the remaining 46, 95\% received income from social security. 100\% responded, "yes," when asked if they knew what a credit card is. However on follow-up questioning none of the participants could offer a completely correct description of a credit card and only $76 \%$ provided even a partially correct answer ("It's a rectangle;" "Plastic with money on it;" "You go to a store and buy stuff with it."). Had the researchers only communicated with a yes/no response mechanism, they would have come away with a rather incomplete perception of the participants' comprehension. Consequently, improving communication, receptive (and expressive), is key to the activities of researchers and service providers alike. Amongst those efforts to improve communication is the individualized functional approach. 
Once an individual's level of receptive communicative capacity has been assessed, there are some methods that have been shown to improve comprehension in both individuals with ID and their typical peers. For example, it appears that an inverse relationship exists between the understanding of an external stimulus and complexity of the stimulus for both these groups (Oetting \& Rice, 1991). This effect is greater in those with ID, perhaps due to neuropsychological deficits mentioned above.

Repeated listening experiences have also been shown to play a significant role in the perception of synthetic speech on the part of individuals with mild-to-moderate intellectual disabilities as well as in typical participants (Koul \& Clapsaddle, 2006). The type of stimulus presented may also have a significant effect on receptive communication in this population. Individuals with ID who were successful at identity matching tasks were better at matching pictures to objects than at matching icons, pantomimes, or speech to objects and that delayed matching tasks were most successful using spoken names (Brady \& McLean, 1998). Slowing down both the pace of communication as well as the pace at which new concepts are introduced has also been suggested as a means of improving receptive communication for individuals with ID (Oetting \& Rice, 1991; Gallagher, 2002).

Interestingly, no differences in receptive communication were observed in one study when individuals with ID were grouped according to sex, age, concurrent mental illness, or concurrent pervasive developmental disability (Cascella 2004). This point also supports the idea that an individualized assessment of receptive communicative capacity may be most appropriate in devising a communication strategy for a given individual, as common demographic information such as age, sex, and concurrent diagnoses have not been shown to be reliably predictive of increased or decreased communicative capacity.

\subsection{Thematic Results: Expressive Communication in Individuals with ID}

In contrast to receptive communication, expressive communication is the area of communicative acts in which an individual attempts to relay information directed externally. Expressive communication is often thought of as speech in typical adults, but in both typical and disabled persons expressive communication comprises a number of complementary non-speech acts as well. This is important because individuals with ID often fail to develop speech or develop only limited speech and language abilities (van der Meer, et al., 2011); the study of non-verbal communication is consequently all the more critical in the ID population (Purcell, Morris, \& McConkey, 1999; Ypsilanti \& Grouios, 2008; Caselli et al., 2008; Iacono et al., 2009; Carvajal et al., 2012). In one study of adults 
with severe ID, expressive communication methods most often observed included reaching gestures, body orientation, facial expression, leading gestures, eye gaze, and vocalizations (Cascella 2005).

There is a wide range of abilities in expressive communication among individuals with ID: some individuals with severe ID may not produce any intentional expressive communication while others with severe ID are capable of intentional communication and also some, albeit limited, symbolic communication (McLean, Brady, \& McLean, 1996; McLean et al., 1999; Cascella, 2005). These results indicate that at least some subset of adults with profound ID possess communication skills that allow them to affect the environment, state choices, and express some needs (Cascella, 2005). Levels of expressive communication can be grouped from lowest to highest into the categories of intentional-contact gesture, intentional-distal gesture, single symbol, and combined symbols (McLean et al., 1999). Given the aforementioned heterogeneity that exists among individuals with ID with respect to their communicative capabilities, the severity of ID in a given person is not necessarily indicative of the level of expressive communication that they can achieve.

In characterizing the expressive communication of individuals with ID, it seems clear that there is a significant reliance on non-verbal communication, often to a greater degree than a typical adult would require. Despite these limitations, individuals with severe ID have been observed to convey an emotional state, make a choice, request a desired object or person, and to convey protest (Cascella, 2005). These observations are the basis of self-determination mechanisms within active treatment models in group, institutional and personal homes across the US (Coehlo \& Kelley, 1993; Code of Federal Regulations [CFR] 42\$483.440).

It has also been observed in multiple studies that in this population protoimperative communicative acts are more frequently initiated than protodeclarative communication acts (McLean et al., 1991; Brady \& McLean, 1995; McLean et al., 1999; Cascella, 2005). Protoimperative acts are those meant to request an object, request an instrumental action, or to express rejection of some type; protodeclarative acts are those meant to request attention toward another or toward the self (McLean et al., 1991; McLean et al., 1999).

In terms of relative abilities in expressive communication among individuals with ID, it has been shown that distal gesture (in which the hand gesture does not come in contact with any other person or object, like pointing towards a toy) and symbolic communicators demonstrate similar communication rates and functions, whereas contact gesture (in which physical contact is made with another person or an object) communicators demonstrate significantly more restricted communication systems. There is also evidence that among non-verbal 
individuals, intentional contact gesture communicators have less robust communication behaviors and tend to communicate for a more restricted range of functions than distal gesture users (McLean et al., 1999). In one study, contact gesture users were also found to be significantly worse in identity object matching than distal gesture users or symbolic participants (Brady \& McLean, 1998).

One development, with recently increasing technological complexity, in improving expressive communication for individuals with ID is the use of augmentative and alternative communication (AAC) technologies. These technologies include simple vocalizations, gestures, American Sign Language, low-tech communication boards, picture-exchange systems, and speechgenerating devices (SGDs) and can facilitate expressive language abilities (Bondy \& Frost, 2001; ASHA, 2002; Lanconi et al., 2007; Cheslock et al., 2008; van der Meer et al., 2011). Symbolic forms of communication with individuals with severe ID may also rely on AAC (ASHA 1992). It has been suggested that AAC systems are effective because they remove the pressure to speak and reduce auditory short-term memory and processing demands (Cheslock et al., 2008). It has also been suggested that delayed matching to sample could be a helpful instructional format when learning to use a selection-based communication system to communicate about absolute referents (Brady \& McLean, 1998).

AAC has been shown to produce gains in communication among individuals with severe aphasia (language impairment) in controlled treatment contexts (Jacobs et al., 2004). For non-verbal adults with severe ID, more recent literature has recommended that language intervention include the use of AAC systems to improve communication and interaction with others (Cheslock et al., 2008). It has also been shown that the use of SGDs by individuals with moderate to profound ID results in an increase in communicative interactions with support personnel and more efficient acquisition and use of graphic communication symbols (Adamson et al., 1992, Schepis \& Reid, 1995; Schlosser et al., 1995). In some studies, SGDs appear to be a more effective means of expressive communication than gestures or vocalizations (Romski \& Sevick, 1994; Koul \& Clapsaddle, 2006). One case report followed the implementation of an SGD as a compensatory strategy to facilitate communication and language abilities in a 30-year-old woman with diagnoses of moderate ID and a severe language disorder; it resulted in both improved communication and social changes (Cheslock et al., 2008).

As with the importance of an individualized assessment of communicative abilities at baseline, it has also been proposed that a preference assessment approach be used to determine the best AAC options for individuals with ID who may benefit, given the variety of AAC and the difficulty of predetermining whether any given communicative option is viable for a given individual. Allowing for 
the individual's abilities and preferences to be taken into account may also be one way to enable them to exert some control over their lives and participate in this clinical decision (van der Meer et al., 2011). Keeping in mind the preferences of the individual, one argument favoring the use of SGDs over other types of AAC in this population is the fact that the addition of voice output to visualgraphic symbols was found to result in more efficient learning than the use of visual-graphic symbols alone (Cheslock et al., 2008).

Individuals with severe to profound ID have historically been given few to no opportunities to make basic choices (Stancliffe \& Abery, 1997; Cannella, O'Reilly, \& Lancioni, 2005), yet research has shown that these individuals are often capable of making and communicating choices (Lanconi, O'Reilly, \& Emerson, 1996; Cannella, O'Reilly, \& Lancioni, 2005). Choice can be defined as "the act of selecting an item or activity from an array of options at a particular moment in time" (Romaniuk \& Miltenberger, 2001).

Research studies on using and developing accurate and concise preference assessments are few but increasing (Kearney \& McKnight, 1997; LohrmannO'Rourke \& Browder, 1998; Cannella, O'Reilly, \& Lancioni, 2005). Of the few studies comparing preference assessments, at least two have found a paired stimulus format to be more valuable to other preference assessment formats when considering consistency of response as well as the efficiency of the assessment (DeLeon \& Iwata, 1996; Roane et al., 1998; Cannella, O'Reilly, \& Lancioni, 2005).

The incorporation of preference assessment may be an important means both for facilitating communication and also for improving the efficacy of various interventions or communicative strategies for individuals with ID. In one study, preferred stimulus conditions produced higher response rates than did baseline or nonpreferred stimulus conditions; this result suggests the importance of assessing the reinforcement value of preferences for individuals with limited behavioral repertoires (Pace et al., 1985). It has also been documented that preferences change over time and may need to be reassessed periodically, if not frequently (van der Meer et al., 2011).

Using the potential for choice interventions and preference assessments to lead changes in the overall protocol for providing services to individuals with severe to profound developmental disabilities is of great importance, and it remains an important area of needed research to develop a way of determining who the best candidates for choice making interventions would be and which choice making strategies would be best suited to these candidates. It is likely that some individuals with ID would benefit more than others from choice making interventions, but thus far no criteria exist for identifying these individuals (Cannella, O'Reilly, \& Lancioni, 2005). 
Regardless of preferred communication mode, it is also important to be aware of potential adaptive response sets that the individual with ID may rely on. An example of this would be acquiescence, in which an individual answers affirmatively to questions that they do not understand regardless of question content (Sigelman et al., 1981; Mansfield \& Pinto, 2008). Such response sets do not necessarily represent the ideas or desires of the individual but instead reflect a learned adaptation and often a lack of understanding. Assuming a more active role on behalf of the communicator attempting to elicit a response from the individual with ID can also facilitate improved expressive communication. Specific best practices in this area include increased prompting, suggesting possible responses, and rephrasing the ideas expressed by the individual with ID with greater frequency (Booth \& Booth, 1996; Gallagher, 2002).

Thus, expressive communicative abilities among individuals with ID are heterogeneous and widely varied. Nevertheless, many of these individuals are able to make choices and communicate preferences, and the elicitation and incorporation of these preferences into the individual's life is an important potential context for expressive communication. The use of AAC, particularly with SGDs, has been shown to assist individuals with ID with successful expressive communication.

\subsection{Conclusions and Best Practices}

Thus far, there have been relatively few studies that have directly examined communication strategies with individuals with ID for the purpose of best practices. However, we find many ways in which communication could be improved with these individuals.

For example, in one study, when speech-language pathologists examined the communicative interactions between individuals with ID and front-line staff in service agencies for people with ID, numerous recommendations could be made to staff personnel to improve communication with their clients. The researchers' recommendations most often included using simpler sentences and words, increasing non-verbal signals and open questions, providing more opportunities for the clients to initiate topics, and increasing their responsiveness to clients' non-verbal signals (McConkey, Morris, \& Purcell, 1999). Given the often tangential investigations conducted so far, some insights can be made based on the available literature regarding evidence-based best practices in improving communication with individuals with ID. 


\section{When attempting to communicate a concept to an individual with ID}

- Assess the level of receptive vocabulary and communicative skills that the individual exhibits. Attempt to conduct such an assessment both for familiar and unfamiliar contexts. Use both familiar care-givers and speech-language pathologists when conducting this assessment with prior training in the assessment methods for both types of assessors when possible.

- Use sentences and words that are as simple as possible.

- Repeat verbal information for the client multiple times.

- Supplement spoken information with non-verbal signals and pictures.

- Check for understanding both immediately after presenting information and also after allowing for a short time delay.

\section{When attempting to elicit and understand an idea being communicated by an individual with ID}

- Recognize that there is great communicative heterogeneity among individuals with ID and that some of these individuals will not produce any expressive communication.

- Utilize caregivers most familiar with the individual to help generate a context and 'vocabulary' of gestures, vocalizations and interpretive structures for the individual's expressive/receptive communication; ideally, however, such caregiver-interpretations should be moderated by communication professionals to minimize over- and under-interpretation.

- Assess the level of expressive communicative skill that the individual exhibits, with particular attention paid to the methods the individual most often relies on to communicate. Attempt to conduct such an assessment both for familiar and unfamiliar contexts. Use both familiar care-givers and speech-language pathologists when conducting this assessment with prior training in the assessment methods for both types of assessors when possible.

- Incorporate both closed and open questions.

- Provide opportunities for the client to initiate topics.

- Offer more suggestions, prompting, and rephrasings of the client's words and ideas than might be expected when working with an individual who does not have ID.

- Be attentive to the client's non-verbal signals, which may include reaching gestures, body orientation, facial expression, leading gestures, and/or eye gaze.

- Be aware that clients may communicate in part through vocalizations that are not words.

- Facilitate the use of a client's SGD or AAC system if available. 
- Incorporate and elicit as many communication choices as possible, allowing the client some control over how they would prefer to communicate as well as over the choice they are being asked to communicate about.

\section{RESULTS: COMMUNICATION WITH INDIVIDUALS WITH PSYCHIATRIC DISABILITIES}

\subsection{Introduction}

Psychiatric disability (PD) refers to a wide range of clinical conditions with diverse etiologies, involving a large variety of functional deficits and mental abilities. As in ID, many of these situations affect communication.

Serious mental illnesses, such as schizophrenia, schizoaffective disorder, and bipolar disorder, provoke consequential functional debilities and are some of the leading causes of disability (Murray and Lopez, 1996; Kessler et al., 2003).

U.S. estimates of PD prevalence are approximately $4.5 \%$

(http://www.nimh.nih.gov/statistics/SMI_AASR.shtml). However, this number is highly subordinate to definitions of PD. Here, PD roughly approximates the more commonly used phrase, "Serious Mental Illness" or SMI. Given the prevalence of PD in the general population and the frequency with which these individuals are served by federal agencies, it is of interest to these institutions to know how to best communicate with this service population.

The purpose of this portion of the review is to examine the current literature on communication with individuals with PD. We will attempt to evaluate what is known regarding the communicative strategies with an aim to determine how the literature may inform a set of evidence-based best practices regarding how to most effectively and efficiently communicate with individuals with PD.

\subsection{Specific Methods}

As previously noted, there is a significant degree of heterogeneity, conflict and methodological/paradigmatic variation among the available PD literature. Consequently, a meta-narrative methodology was deemed to be more valuable than a more traditional meta-analytic prioritization approach.

Literature searches for this portion of the project relied mainly on the PubMed by the National Institutes of Health and SocINDEX by EBSCO Publishing databases. Initial searches included terms such as "adults," "mental illness," 
"communication," "schizophrenia," "bipolar disorder," "psychotic," "receptive," "expressive," and "language." In this process, key papers were identified and a snowballing technique (searching references of references and using citationtracking databases) was used as a means of hierarchical source generation in gathering the most relevant literature.

We identified key sources by asking what references were cited as key original and scholarly contributions by other researchers in the same tradition. From this collection of material, we read the primary sources and have summarized their key findings and used the concepts, theories, and preferred methods therein to guide our appraisal of empirical studies. We gave somewhat greater weight to studies that have been flagged as "high quality" by other scholars in a tradition, but because the literature includes an unusually wide range of different paradigms, perspectives, and study designs, we did not use a formal quality scoring system.

References were cataloged using Endnote Web. Access to journal articles, scholarly databases, and citation management was through the library resources of the University of Wisconsin - Madison.

From a much larger sample, in all, 68 key references were identified, which examined the topics of language development and use, communicative abilities, and preference assessment for individuals with PD.

At the outset, it should be acknowledged that we've detected no coherent literature specifically addressing how to communicate with individuals with PD. For example, of 1810 studies that could relate to communication support/lifestyle interventions for those with schizoaffective disorders and diabetes mellitus, type II, only 4 were valuable for inclusion in a synthetic analysis (Cimo et al., 2012). This is strongly suggestive both of the paucity and lesser quality of the literature currently extant. However, there are some relevant results in other categories.

The pertinent papers were organized roughly into the following thematic categories:

- written- and internet-based psychoeducation;

- user development of psychoeducational material;

- psychoeducation and/or health communication with those with PD, e.g., interventions to improve adherence to medication in schizophrenic patients. Few foundational pieces appear in this theme and little explicitly deals with basic principles for communicating with, e.g., psychotic patients; 
- psychoeducation of mentally ill patients' families--consensus is that patient families should be involved;

- assessment of those with PD to participated in Psychiatric Advanced Directives and Shared Decision Making, activities comparable to addressing complex paperwork and decision making in situations of governmental support;

- retention of participants from difficult subject populations in clinical trials (includes homeless, substance use, and mentally ill), because communication involved means of best contacting these individuals and building rapport;

- research on face-to-face and/or telephone communication, e.g. training nurses how to interview schizophrenic patients and implementation of mental health services in communities, with special emphasis on emergency communication;

- finally, there is a wealth of literature on specific cognitive impairments of individuals who also have PD, but this wealth rarely invokes communication. Weeding out that little result would require extensive work beyond the above remit, without clear likelihood of significant value/relevance.

\subsection{Thematic Results: Written- and Internet-based Psychoeducation}

For individuals with PD, a uniform theme is that written communication is often efficacious as a medium of information exchange. Despite the receptive impairment of cognitive defects, written material often transmits significant amounts of data. Equally, and especially when augmented with face-to-face support, therapeutic value attends written communication.

It is noteworthy that one assessment of different methods of patient education for individuals with schizophrenia did not find any difference between computer-based communication, conventional (paper leaflet), and groups given information orally in an inpatient setting. Their conclusion is that patients can be educated via leaflet, computer or in person equally well (Pitkänen et al., 2012).

Nevertheless, there is emerging, if not rock-solid, evidence that multi-media communication promises valuable results. Interactive and self-guided media have proven effective, especially in psycho-education. Online efforts, for example, have embraced support groups and blogs, Skype and webcams, interactive, selfguided interactions, as well as SMS and handheld device apps (Barak \& Grohol, 2011). However, few randomized controlled trials support solid evidence-based conclusions. Confounders frequently involve co-morbidities like ID and variation in support staff for the individual consumer with PD (Jeste et al., 2006). 
Despite these limitations, initial results suggest that online therapy is as effective as person-to-person therapy, although nonverbal cues are often lost in the digital transmission (Barak, et al., 2008; Gainsbury \& Blaszczynski, 2010; Barak \& Grohol, 2011; Stjernswärd, 2011). While demographic data is as yet unstudied, preliminary investigation posits that there may be a mild gender preference for efficacy in women with online therapy (Gainsbury \& Blaszczynski, 2010). Consequently, strong consideration needs to be given to individual needs and particularized programs (Menon \& Miller-Cribbs, 2002; Rahman (ed.), 2006).

A driver of interest in internet-based communication is perceived value. Obvious benefits include: a reduction of pressure for time-sensitive responses (as in face-to-face communication), anonymity (with avoidance of stigmatization), flexibility of access (in terms of time of day and transportation), as well as costreduction. Nevertheless, observed drawbacks include risk of breeched confidentiality, internet aggression (especially in groups), computer-induced isolation behavior, sleep disregulation from computer use, technological fluency as a barrier, and technical design limitations. These latter design considerations involve the impact of PD (and ID) in receptive barriers, the need for minimized distractions on the screen, the use of multi-format presentation (e.g., video as well as text and aural), maintenance, content quality assurance, avoidance of stigmatizing language/imagery, tracking/confidentiality, and the necessity of enhanced flexibility for users (i.e., which may require in-person support).

When examining computer-based communication, one can differentiate between synchronous (real-time) and asynchronous (e.g., email, bulletin boards, etc.) mechanisms. In general, synchronous communication costs as much as face-toface communication; asynchronous communication is less expensive.

Some work in this narrative theme suggests that asynchronous communication may reduce misunderstandings in communication because of increased time between query and reply as well as individualized flexibility of access (Efstathiou \& Kalantzi-Azizi 2008; Barak \& Grohol, 2011; Stjernswärd, 2011). As one summary emphasized, "staying at home even when regularly taking classes, asynchronous communication brainstorming and socialization, course material flexibility, and accommodation (in terms of colors, fonts, and formats) allow people with mental illness to better cope with symptoms, and possibly complete course materials and assignments even in conditions under which they would not be able to go to school and perform" (Rahman (ed.), 2006).

College students, at least, were eager consumers of mental health, asynchronous support, with clear acknowledgment of higher quality information offered in controlled sites compared with the generic results of unbridled internet searches; indeed, the searchability of anonymous questions and posted results was quite 
compelling. Nevertheless, internet ethical concerns remain consequential (Efstathiou \& Kalantzi-Azizi, 2008; Stjernswärd, 2011; McKay \& Martin, 2012). A variety of models for enhancing academic-based mental health support for students has been proposed, though not tested (McKay \& Martin, 2012).

While set in Taiwan, another study identified opportunities and challenges in informational communication for those with PD. Many did not have computers of their own, necessitating sharing with other family members. This characteristic encouraged family participation while hampering privacy. Poor computer problem-solving skills could be accentuated by the underlying PD, as when paranoiac or obsessive tendencies focused on concerns over computer viruses. Heterogeneity of diagnoses brought specific challenges to light. For example, schizophrenic patients had difficulties in computer use because of disease-related features like cognitive (problems with attention and problemsolving, etc.) and physical (hand tremors from medication make using a mouse difficult) sequelae. Nevertheless, in that study, a series of specific recommendations to improve computer communication with individuals with ID included individuated tailoring of the computer and software to each user, repeated Information Technology support for the individual, virus-free hardware access, and simplification of access to key information with significantly minimized key strokes or mouse clicks (Huang et al., 2007). Some of the social dynamic challenges are borne out in the American context as well (McKay \& Martin, 2012).

\subsection{Thematic Results: Design of Written Communicative Materials for Psychoeducation, Including Users in Development}

In this theme, the literature most closely approximates some of the principles of the disability rights movement. Signally, data supports involving users (i.e., individuals with PD) in design of materials and services, with researchers arguing that such participation is crucial and consequently results in better outcomes (Tait \& Lester, 2005 provides a nice rationale).

While some studies find no differences, overall, user-run and user-led services often show evidence for better efficacy, improved user satisfaction and improved user quality of life (Doughty \& Tse, 2005; Mockford et al., 2011; Garces et al., 2012). However, this is not always an easy initiative to follow; barriers to involvement include unwillingness/poor training on the part of service providers, and stigma or lack of education on the part of users. Training of both parties is frequently stressed to promote success. 
A few strands of the narrative (Välimäki et al., 2008; Wingwood \& DiClementi, 2008; Druss et al., 2010) describe procedures for adapting information for audiences with PD. One studied six sites undergoing a process of involving mental health service users to redesign communicational (informational) tools. Their basic conclusions included: a) service user involvement was beneficial but there were barriers, including cultural/practical hurdles; b) it is necessary to include more than one user on a panel so the person isn't singled out; c) requirement for an open environment where users and providers work together and users do not feel marginalized; $d$ ) service users need training or facilitation for how to best express their opinions in this context; staff likewise need training in how to best work with service users (Robert et al., 2003).

But the embrace of end-user involvement should not be monovalent. Others have argued that at least four levels of collaboration should occur: a) in the interaction between service users and in the form of self-help; $b$ ) in the interaction between individual users and professionals working with them; c) in the management of local services; and d) in the planning of overall services (Tait \& Lester, 2005).

As indicated in the ID section, best practices may include a minimalist standard of educational attainment for written material in communicating with individuals with ID. At least one study has advocated a sixth-grade reading level, augmented by the HIV-driven implementation techniques of the ADAPT-ITT study (Druss et al., 2010). ${ }^{4}$

Analysis of such efforts in disease specific settings under the broader rubric of PD is only just beginning (e.g. with Bipolar Disorder) (Syrett, 2011). One group focused on end-user involvement in generating written content for online presentation around schizophrenia alone. While 'quality assurance' was maintained using professional/expert advice, extensive surveying/interviewing of end-users with schizophrenia was supplemented with multiple sequential interactions in user re-evaluation of generated material at each stage of production and presentation. The resulting experience for the users was significantly enhanced (Välimäki et al., 2008).

${ }^{4}$ ADAPT-ITT is a protocol for adapting evidence-based interventions to different populations and utilizes an 8-step progression to that end: Assessment, Decision, Administration, Production, Topical Experts, Integration, Training, and Testing; see Wingwood \& DiClementi, 2008. 


\subsection{Thematic Results: Interventions to Manage Care / Improve Medication Adherence among Adults with Serious Psychiatric Disabilities}

While much of the peri-communicative literature in PD relates to psychotherapy or holistic support, one theme emphasizes a concrete end-point, namely the acquisition and maintenance of medication regimes. Communication to this end represents a degree of social control or social management.

In general, the communicative strategies in this theme involve cognitive reinforcement (for example, emphasizing memory-based reminders for taking medications) or structural access (for example, financial or physical access to clinics or pharmacies). Shared qualities of the communicative solutions were on simplicity and concreteness.

One review of strategies for improving healthcare engagement among those with schizophrenia emphasized that, "an emerging literature on patient-centered care and shared decision making in psychiatry provides suggestive evidence that efforts to enhance client-centered communication and promote individuals' active involvement in mental health treatment decisions can also improve engagement in treatment," thus echoing the findings of written materials for psychoeducation (Kreyenbuhl et al., 2009).

Another review of management approaches stressed the lack of evidence for efficacy of trying to specifically change attitudes amongst those with PD. Rather, there was clearer support for programs removing logistical barriers or offering environmental help. That support was even more evident for those with both ID and PD (Roberts \& Velligan, 2011).

Intriguingly, in one survey, nearly three-quarters of those with serious PD have mobile devices; of these more than four-fifths are interested in linking health services through the devices. On the other hand only three-fifths of those without the devices are so inclined. There is little extant research to support best practices in this direction (Ben-Zeev et al., 2012). But one study argues that cell phones can be effectively used to provide communicative support for increased medical adherence (Burda et al., 2012). Another study effectively used cell phone reminders to improve keeping appointments (Sims et al., 2012).

Communication intended to change negative practices or to reinforce positive practices was most likely to be 'effective' when conveyed in positive, simple, repetitive (reinforcing) and gradual messages (Zygmunt et al., 2002; Cimo et al., 2012). On the one hand, at least at the level of medical interventions and costs, six studies invoking some of these strategies had no effect on costs or outcome measures (Garcia-Perez \& Serrano-Aguilar, 2011). On the other hand, telephonic 
case management for this population has been shown to reduce both costs and recidivism (Kolbasovsky et al., 2010).

Where simplicity may be valuable, complex communication is also at times important. For example, family involvement and anticipatory planning for repetitive meetings/sessions was found valuable (Steffen et al., 2009). And there is some indication that a treatment model employing assertive community involvement or motivational interviewing may prove beneficial (Zygmunt et al., 2002).

Finally, specialized training for the professional support staff needs to be highly focused on the conditions involved and their co-morbidities (Happell et al., 2012). Despite the necessarily medical focus of these studies, it is clear that health care providers for individuals with PD recognize their potential to help navigate the social support and entitlement systems, but they often feel inadequate to do so; this was particularly evident in a qualitative study of communication of nurse supporters for individuals with PD (Kahn et al., 2009).

\subsection{Thematic Results: Involvement of the Family in Education and Care}

One component of communication for the individual with PD involves their micro-community - family (Rowe, 2011). In the lived experience of identification, treatment and support of individuals with PD, no support surpasses the intimacy of biological and socially validated family. However, families often feel marginalized, ignored or even excluded from information-gathering and decision-making.

Hand-in-glove with family involvement is the issue of confidentiality, autonomy and divided decision-making (Rowe, 2011). Nevertheless, given the aforementioned intimacy and the negative effects of family exclusion, family engagement, involving concrete, logistical elements can be most beneficial. Training of professionals in principles of respect, autonomy and legal/regulatory / guideline-based boundaries is crucial to successfully navigating the benefits and challenges of family involvement. A number of models, if not formally evaluated as best practices, exist for consideration/adaptation, including a consultative model (Schmidt \& Monaghan, 2012).

In particular, early family engagement (even briefly), especially around mechanical issues of access, scheduling, and transportation, reduced psychological barriers to cooperation/collaboration. While brief interactions yields dividends, long-term family engagement, at multiple points in the support 
process yielded the greatest benefits (McLendon, 2008; Ingoldsby, 2010; Rowe, 2011).

This engagement, in a clinical setting can actually involve clinical care of the family as well, recognizing the impact of PD beyond the boundaries of the individual (Luciano et al., 2012). Such observations provoke the well-trod trope that SSA support impacts not only the individual receiving SSI/SSDI, but also their family. Consequently, if decision-making will occur within the family as a result of governmental support (or clinical care), communication and education may best occur at the level of the family as well, albeit, within the limits of confidentiality and autonomy.

While lessons generated from children with PD and their parents can be inappropriately applied to adults, some data may be applicable (McLendon, 2008; Ingoldsby, 2010). In this setting, hope seems critical to the long-term motivation of collaborative services. That hope can be inspired by stressing individual and family extant strengths at the outset. McLendon, in particular, emphasizes best practice standards for such engagement and the consumer benefits accruing therefrom.

\subsection{Thematic Results: Ability of Psychiatric Patients to Communicate, including Psychiatric Advanced Directives (PADs) and Ability to Participate in Shared Decision Making (SDM)}

Just as family is important, so too is the individual themselves. Distinct from the role of individuals with PD as consumer informants, the nature of shared decision making (SDM) and psychiatric advanced directives (PADs) places autonomous activities squarely in the individual's court.

This narrative reinforces the impression that individuals with PD frequently have challenges with communication. These challenges include poor insight and deficiencies in pragmatic language use (Chan \& Mak, 2012). One study identified functional disturbances by sample frequency for 191 individuals with PD:

- Cognitive functional disturbance: $70 \%$ of sample

- Social: $41 \%$ of sample

- Emotional: $50 \%$ of sample

- Physical/other: $32 \%$ of sample (MacDonald-Wilson et al., 2003).

Despite the effect of these functional disturbances on communication, there is a strong desire on the part of individuals with PD for SDM. Much like the result of 
the healthcare consumer rights movement of the 1960s-90s for those without PD (or ID), those with PD often actively want to have autonomous choice (Patel et al., 2008). When afforded the opportunity for SDM, patient outcomes are often better. Service providers thus have an increased responsibility to overcome communicative barriers.

Important skills in communicating verbally with individuals with PD (Bowers et al., 2009) include: comfortably being with the patient (often in silence), engaging in the current environment and its distractions, tolerating hallucinations during conversation, and keeping things simple while repeating points. Indeed, Bowers' piece provides an excellent summary of strategies for supporting those with psychosis.

Generic guidance for maximizing receptive communication involves assessing the individual's current cognitive functioning at the moment of contact (especially as this may change over time) and then tailoring conversations (and written materials) to current functional capacity. Interventions to enhance decision-making ability and/or communication skills may facilitate dialogue, such as a brief decision-making intervention. This in turn involves talking to the patient for $<1$ hour to explain aspects of the process or brief therapies focused on pragmatic language use, cognitive remediation, metacognitive skills, etc. The result is at once therapeutic and tends to improve the quality of the process.

After initial assessment, ongoing dialogue, rather than one-time problem-solving, as a paradigm, adds value to the client's experience and minimizes the pressure to simultaneously solve a technical issue while also navigating communicational barriers. The longitudinal approach allows service providers to revisit issues over time promoting more success especially since cognitive function may wax and wane (Lysaker, et al., 2010; Lysaker, et al., 2011a; Lysaker, et al., 2011b; Chan \& Mak, 2012).

Nevertheless, even a one-time workshop can improve some target behaviors, like increasing research participation following a workshop to communicate the goals and mechanisms of the research (Cleary et al., 2008). Likewise, communication with those with significant PD can be improved with brief interventions (Kramer et al., 2001). In this latter case, two individuals with profound schizophrenia were able to improve their communicative skills using a discourse frameworkbased brief therapy. But in cases involving both PD and ID, compound/adjunctive therapy is necessary to meet the overall therapeutic goals (Patterson \& Leeuwenkamp, 2008).

Having a counselor or other trained staff person to help the individual go through a process of assimilating information and descision-making can be very 
helpful as can involving family members. Distinct from the less personalized workshop approach, one-on-one communication, not surprisingly, promotes focal guidance (Elbogen et al., 2007).

While stress has been placed in this theme on family and other external support, great caution should be used to avoid underestimating the ability of the individual with PD to communicate. Psychiatric Advanced Directives (PAD) are complex legal and social documents, which are cognate to the complexity of some of the issues for SSA or other governmental agencies. The literature suggests that most patients with PD are competent to complete a PAD (meaning they can communicate and understand their condition and the implications of their decisions); in fact, there is no need to assess competence in most patients, unless there is specific reason to suspect lack of competence. In such situations, there are validated tools for assessment (Srebnick \& Brodoff, 2003; Srebnick et al., 2004; Srebnick \& Kim, 2006; Wilkinson et al., 2007; Van Dorn et al., 2008).

Moreover, most patients are able to communicate sufficiently well that one may assess their symptoms of PTSD. In other words, patients with severe PD are capable of being interviewed and of filling out forms, etc., i.e., they are able to communicate well enough to assess subtle PTSD symptoms in spite of other psychiatric diagnoses (Rosenberg et al., 2001).

In sum, people with PD want to be involved. Generally they welcome information and the ability to participate in decision-making. For advanced directives and SDM, two complex cognitive activities, there is benefit to having the patient involved. Consequently, similar activities for governmental agencies might be amenable to some of the communication strategies above.

\subsection{Thematic Results: Strategies to Enhance Satisfaction of Individuals with Psychiatric Disabilities; Includes Studies on Patient Satisfaction in Healthcare Settings and of the Experiences of Students with Psychiatric Disabilities in Higher Education}

One comparable venue of communication is satisfaction assessment for individuals with PD. Research in this vein has predominantly come from evaluation in healthcare settings. But a small number involves students with PD in higher education.

In healthcare quality evaluations, targeted feedback from and analysis of systems involving individuals with PD suggest several common points. Concern for stigmatization is seminal amongst individuals with PD interacting with larger social structures (Spaniol, 2001; Happell, 2008; Drake \& Latimer, 2012; McKay \& 
Martin, 2012). This theme appears in the higher education literature as well (Martin \& Oswin, 2010).

Included in the power of stigmatization is the need for people-first language. This latter expectation emerged from the Disability Rights movement of the 1980s and 90s both in the US and the UK, highlighting that there is a markedly different message between labeling someone, a "disabled person," as opposed to a "person with a disability."

Especially for individuals with PD, intra-professional communication is also critical (Byng \& Jones, 2003; Drake \& Latimer, 2012). Lack of coordination between various levels of care providers, groups and agencies, especially around shared communication goals and values can consequentially undermine trust / rapport with individuals with $\mathrm{PD}$, who are already prone to suspicion because of stigmatization.

While representing a philosophical emphasis on autonomy, self-determination also promotes a structure of mutual trust, collaboration and attention to the expressive nature of the individual with PD (Spaniol, 2001). It equally mitigates unintentionally coercive processes, while stressing recovery and creativity. Consumer-run/-led heuristics of self-determination, such as supported housing, supported employment, supported education, and strengths-case-management, demonstrate, in early evidence-based models, the lessons of self-determination (Drake \& Latimer, 2012). In particular, a consumer-model (see 4.4, above) stresses the involvement of individuals with PD in the design of systems of care that they will then consume. Such involvement at once promotes trust through collaboration and respect through client empowerment. It also requires that the supporting agency find ways to receive expressive communication from the client themselves (Happell, 2008).

Peer support is also a strong theme from this literature. Interaction with peers equally promotes client empowerment while augmenting shared communication; this can provide long-term community benefits to the agency seeking to communicate (Happell, 2008; Drake \& Latimer, 2012). Many of these same points emerge in family engagement and communication (Spaniol, 2001).

While structurally different in a number of key characteristics, academic institutional communication with students with PD echoes similar themes. Thus, respect and empathy for the individual, rather than emphasis of the label/diagnosis, emerges from two publications. More so than in the healthcare agency literature, pedagogic institutions stress the need for flexibility on the part of the institution, emerging from a valuation of empathy and promoted 
autonomy (Martin \& Oswin, 2010; Brockelman, 2011). Both literatures stress the need for anticipatory training and planning on the part of staff.

\subsection{Thematic Results: Tracking \& Follow-up of Marginalized Populations in Studies}

The social control needed to involve at-risk populations in research is complex and provokes comparison with the PD and ID populations discussed in this review. Consequently, a strain of research that is suggestive for our focus involves ways to recruit, manage and follow-up with marginalized populations in research.

Two valuable publications provided concrete insights. Hall et al., 2003 offers a field manual for locating substance abusers for follow-up studies. A key in their effort was to build communication and follow-up strategies into the initial contact.

Part of their anticipatory strategy involved detailed location mechanisms for future contact (given the mobile nature of people with PD). More valuable was an emphasis on flow chart-decision trees for contact, including utilization of local and regional governmental agencies (e.g., DMV, sheriff/police), health care and private corporate (e.g., telephone or credit agencies), as well as postal institutions to maintain contact with individuals who have a propensity to move without typical preference for governmental contact, like many with PD.

Similar stresses on organized identification and tracking of marginalized populations invoke differential incentive systems, confidentiality and rapport. Equal measures of staff training and attention to bilateral safety concerns should be combined with vigorous, pro-active documentation (McKenzie et al., 1999).

\subsection{Thematic Results: Sending out Information to Vulnerable Communities in Case of Emergencies}

Another setting in which communication with individuals with PD (as well as ID) requires generalizable principles is in the setting of emergency preparedness. While only one study fell into this category, there is emerging awareness of the challenges for governmental agencies to anticipate heterogeneous communication needs for their target populations. In the wake of 9/11, accelerating changes in this area bear watching.

Nsiah-Kumi (2008) highlighted some points also in our review for ID, including the receptive, productive and processing variability of individuals with PD from typical individuals as well as from each other. This study, however, also stressed 
variability across community and institutional settings. As may be expected in a pioneering piece, the emphasis was on future needs, including the obligation to involve families, caregivers and health care providers, as well as the need for training in effective techniques of communication

\subsection{Conclusions and Best Practices}

Many of the principles suggested in $\mathbf{3 . 6}$ for ID pertain equally for PD.

\section{When attempting to communicate a concept to an individual with PD}

- Assess the level of receptive vocabulary and communicative skills that the individual exhibits. Endeavor to conduct such an assessment both for familiar and unfamiliar contexts. Use both familiar care-givers and psychological support staff when conducting this assessment when possible.

- Use sentences and words that are as simple / unambiguous as possible.

- Repeat verbal information for the client multiple times.

- Check for understanding both immediately after presenting information and also after allowing for a short time delay.

\section{When attempting to elicit and understand an idea being communicated by an individual with PD}

- Recognize that there is great communicative heterogeneity among individuals with PD, particularly confounded by co-morbidities and that some of these individuals will not produce any expressive communication or very contrarian communication.

- Utilize caregivers most familiar with the individual to help generate a context and 'vocabulary' for the individual's expressive/receptive communication; ideally, however, such caregiver-interpretations should be moderated by psychological professionals to minimize over- and under-interpretation.

- Assess the level of expressive communicative skill that the individual exhibits, with particular attention paid to the methods the individual most often relies on to communicate. Attempt to conduct such an assessment both for familiar and unfamiliar contexts. Use both familiar care-givers and psychological professionals when conducting this assessment with prior training in the assessment methods for both types of assessors when possible.

- Incorporate both closed and open questions.

- Provide opportunities for the client to initiate topics. 
- Offer more suggestions, prompting, and rephrasings of the client's words and ideas than might be expected when working with an individual who does not have PD.

- Incorporate and elicit as many communication choices as possible, allowing the client some control over how they would prefer to communicate as well as over the choice they are being asked to communicate about.

Distinct from the ID themes, the PD narratives also offer general suggestions about programmatics.

\section{When fashioning in-the-field policies relating to those with PD:}

- Incorporate multiple levels and iterations of client participation, at the design, implementation, assessment and re-design phases.

- This is not always an easy process; barriers to involvement include unwillingness/poor training on the part of service providers, and stigma and lack of education on the part of users

- Training of both parties is crucial to ensure success

- A general theme of needful communication seems to be that the biggest issues are either cognitive (e.g., forgetting to take medications) or logistical (can't afford medications, can't access clinic).

- Successful interventions shared features of involving concrete steps/concrete skills or training and removing logistical barriers rather than changing attitudes:

- Simple, clear and/or concrete messages

- Concrete problem-solving skills

- Including memory aids, reminders (e.g. text message)

- Logistical and/or environmental support.

- These individuals may have very complex needs

- Relationship between interventionist and individual is important

- Issues of stigma \& mistrust

- Empathy and support are important

- Involving the family and/or providing education to the family are important factors

- Written communication is efficacious, as patients are generally able to use these in spite of cognitive deficits, etc. A few papers (Välimäki et al., 2008; Wingwood \& DiClementi, 2008; Druss et al., 2010) describe procedures for adapting information for mentally ill audiences.

- Consider the utility of "multimedia" communication, including videos, as this shows promise (interactive/self-guided interventions have proven effective (for instance, in psychoeducation) asynchronously).

- Internet-based communication will likely be useful, since it:

- gives patients time to think over responses so less pressure 
- is anonymous; avoids stigma

- can be accessed at any time, and from home with flexible use

- writing about their disorders can be directly beneficial to patients

- much less expensive than phone calls or in-person visits BUT has some potential drawbacks:

- confidentiality

- in the case of support groups: flaming, internet aggression, etc.

- technological barriers: not everyone has access to computers, not everyone equally technologically savvy

- Over-arching qualities of successful programs included:

- Flexibility

- Empathy and support

- Respectful communication; being treated as an individual rather than a label

- Getting more information

- Being involved in design of materials and services

- Coordination of service teams

- Personal empowerment

- Peer support; community

- People who are likely to work with the mentally ill patient should receive specialized training.

\section{General Conclusions}

The most common theme emerging from the narratives is one of heterogeneity. The methodologies of the meager number of studies available is heterogeneous. The range of conditions both within ID and PD and between them is heterogeneous. The communication abilities and needs of the individuals with ID / PD is highly heterogeneous. And the relationship of the individuals with their families and wider communities is heterogeneous.

While it may seem fatuous to stress, such remarkable variability naturally resists the homogenizing influence of a power bureaucratic structure like governmental programs.

Clearly, much more research, synthesis and policy extrapolation remain to be done in order to translate effectively policy goals into lived experience. Nevertheless, core guidance emerges in this review:

- Respect for the autonomy of the individuals being served (client).

- Sensitivity to the stigmatizing power of labeled disabilities.

- Active involvement of the clients in the design of programmatics. 
- Individualization of communication strategies to meet the specific needs of the particular client.

- Multidisciplinary collaboration, cooperation and communication in order to facilitate communication with the client.

- Family and/or community collaboration, within the boundaries of confidentiality requirements.

- Ongoing exploration of both newfangled and traditional media of communication. 


\section{Works Cited}

\subsection{References (ID)}

Abbeduto, L., Furman, L., \& Davies, B. (1989). Relation between the receptive language and mental age of persons with mental retardation. Am J Ment Retard, 93, 535-543.

Abbeduto, L., \& Nuccio, J.B. (1991). Relation between receptive language and cognitive maturity in persons with mental retardation. Am J Ment Retard, 96, 143-149.

Adamson, L.B., Romski, M.A., Deffebach, K., \& Sevcik, R.A. (1992). Symbol Vocabulary and the Focus of Conversations: Augmenting Language Development for Youth With Mental Retardation. Journal of Speech $\mathcal{E}$ Hearing Research, 35, 1333.

Association, A.S.-L.-H. (2002). Augmentative and Alternative Communication: Knowledge and Skills for Service Delivery. www.asha.org/policy.

Belva, B.C., Matson, J.L., Sipes, M., \& Bamburg, J.W. (2012). An examination of specific communication deficits in adults with profound intellectual disabilities. Res Dev Disabil, 33, 525-529.

Berry, P.B. (1972). Comprehension of possessive and present continuous sentences by nonretarded, mildly retarded, and severely retarded children. Am J Ment Defic, 76, 540-544.

Bloomberg, K., West, D., \& Projects, S.C.I.O. (1999). The Triple C: Checklist of Communication Competencies Manual: Communication Resource Centre SCOPE.

Bondy, A., \& Frost, L. (2001). The Picture Exchange Communication System. Behav Modif, 25, 725-744.

Booth, T., \& Booth, W. (1996). Sounds of Silence: narrative research with inarticulate subjects. Disability \& Society, 11, 55-69.

Brady, N.C., \& McLean, J.E. (1995). Initiation and repair of intentional communication acts by adults with severe to profound. Journal of Speech $\mathcal{E}$ Hearing Research, 38, 1334. 
Brady, N.C., \& McLean, L.K. (1998). Simultaneous and delayed matching to sample in gesture users and speakers with mental retardation. Research in Developmental Disabilities, 19, 409-421.

Cannella, H.I., O’Reilly, M.F., \& Lancioni, G.E. (2005). Choice and preference assessment research with people with severe to profound developmental disabilities: a review of the literature. Research in Developmental Disabilities, 26, 1-15.

Carlesimo, G.A., Marotta, L., \& Vicari, S. (1997). Long-term memory in mental retardation: evidence for a specific impairment in subjects with Down's syndrome. Neuropsychologia, 35, 71-79.

Carvajal, F., Fernández-Alcaraz, C., Rueda, M., \& Sarrión, L. (2012). Processing of facial expressions of emotions by adults with Down syndrome and moderate intellectual disability. Research in Developmental Disabilities, 33, 783-790.

Cascella, P.W. (2004). Receptive communication abilities among adults with significant intellectual disability. Taylor \& Francis Ltd., pp. 70-78.

Cascella, P.W. (2005). Expressive Communication Strengths of Adults With Severe to Profound Intellectual Disabilities as Reported by Group Home Staff. Communication Disorders Quarterly, 26, 156-163.

Cascella, P.W. (2006). Standardised speech-language tests and students with intellectual disability: a review of normative data. J Intellect Dev Disabil, 31, 120-124.

Caselli, M.C., Monaco, L., Trasciani, M., \& Vicari, S. (2008). Language in Italian children with Down syndrome and with specific language impairment. Neuropsychology, 22, 27-35.

Cheslock, M.A., Barton-Hulsey, A., Romski, M., \& Sevcik, R.A. (2008). Using a speech-generating device to enhance communicative abilities for an adult with moderate intellectual disability. Intellect Dev Disabil, 46, 376-386.

Code of Federal Regulations [CFR] 42\$483.440.

Coelho, R.J., \& Kelley, P.S. (1993). An experimental investigation of an innovative community treatment model for persons with a dual. Journal of Rehabilitation, 59, 37. 
Conyers, C., Doole, A., Vause, T., Harapiak, S., Yu, D.C., \& Martin, G.L. (2002). Predicting the relative efficacy of three presentation methods for assessing preferences of persons with developmental disabilities. J Appl Behav Anal, $35,49-58$.

DeLeon, I.G., \& Iwata, B.A. (1996). Evaluation of a multiple-stimulus presentation format for assessing reinforcer preferences. J Appl Behav Anal, 29, 519-532; quiz 532-513.

Drainoni, M.-L., Lee-Hood, E., Tobias, C., Bachman, S.S., Andrew, J., \& Maisels, L. Cross-Disability Experiences of Barriers to Health-Care Access: Consumer Perspectives. Journal of Disability Policy Studies, 17, 101-115.

Flory J. \& Emanuel, E. (2004). Interventions to improve research participants' understanding in informed consent for research: A systematic review. JAMA, 292, 1593-601.

Gallagher, E. (2002). Adult Clients With Mild 'Intellectual Disability': Rethinking Our Assumptions. Australian \& New Zealand Journal of Family Therapy, 23, 202-210.

Guidelines for meeting the communication needs of persons with severe disabilities. National Joint Committee for the Communicative Needs of Persons with Severe Disabilities. (1992). ASHA Suppl, 1-8.

Havercamp, S.M., Scandlin, D., \& Roth, M. Health Disparities Among Adults with Developmental Disabilities, Adults with Other Disabilities, and Adults Not Reporting Disability in North Carolina. Public Health Reports, $119,418-426$.

Hippolyte, L., Iglesias, K., Van der Linden, M., \& Barisnikov, K. (2010). Social reasoning skills in adults with Down syndrome: the role of language, executive functions and socio-emotional behaviour. J Intellect Disabil Res, $54,714-26$.

Hochhauser, M. (2004). Informed Consent. Reading and Understanding Are Not The Same. Applied Clinical Trials, 13, 42-44.

Hollenweger, J., \& Moretti, M. (2012). Using the International Classification of Functioning, Disability and Health Children and Youth version in education systems: a new approach to eligibility. Am J Phys Med Rehabil, 91, S97-102. 
Iacono, T., West, D., Bloomberg, K., \& Johnson, H. (2009). Reliability and validity of the revised Triple C: Checklist of Communicative Competencies for adults with severe and multiple disabilities. J Intellect Disabil Res pp. 44-53.

Jacobs, B., Drew, R., Ogletree, B.T., \& Pierce, K. (2004). Augmentative and Alternative Communication (AAC) for adults with severe aphasia: where we stand and how we can go further. Disabil Rehabil, 26, 1231-1240.

Kail, R. (1992). General slowing of information-processing by persons with mental retardation. Am J Ment Retard, 97, 333-341.

Kearney, C.A., \& McKnight, T.J. (1997). Preference, choice, and persons with disabilities: a synopsis of assessments, interventions, and future directions. Clin Psychol Rev, 17, 217-238.

Kessler, R.C., Barker, P.R. et al. (2003). Screening for Serious Mental Illness in the General Population. Archives of General Psychiatry, 60, 184-9.

Koul, R., \& Clapsaddle, K.C. (2006). Effects of repeated listening experiences on the perception of synthetic speech by individuals with mild-to-moderate intellectual disabilities. AAC: Augmentative \& Alternative Communication, 22, 112-122.

Kurtz, P.F., Boelter, E.W., Jarmolowicz, D.P., Chin, M.D., \& Hagopian, L.P. (2011). An analysis of functional communication training as an empirically supported treatment for problem behavior displayed by individuals with intellectual disabilities. Research in Developmental Disabilities, 32, 2935-2942.

Lancioni, G.E., O'Reilly, M.F., \& Emerson, E. (1996). A review of choice research with people with severe and profound developmental disabilities. Res Dev Disabil, 17, 391-411.

Lancioni, G.E., O'Reilly, M.F., Cuvo, A.J., Singh, N.N., Sigafoos, J., \& Didden, R. (2007). PECS and VOCAs to enable students with developmental disabilities to make requests: an overview of the literature. Research in Developmental Disabilities, 28, 468-488.

Lohrmann-O'Rourke, S., \& Browder, D.M. (1998). Empirically based methods to assess the preferences of individuals with severe disabilities. Am J Ment Retard, 103, 146-161.

Luckasson, R., \& Schalock, R.L. (2012). Defining and applying a functionality approach to intellectual disability. J Intellect Disabil Res, Jun 6. doi: 10.1111/j.1365-2788.2012.01575.x. [Epub ahead of print]. 
Mansfield, P.M., \& Pinto, M.B. (2008). Consumer Vulnerability and Credit Card Knowledge Among Developmentally Disabled Citizens. J Consumer Affairs, $42,425-38$.

Matson, J.L., Horovitz, M., Kozlowski, A.M., Sipes, M., Worley, J.A., \& Shoemaker, M.E. (2011a). Person characteristics of individuals in functional assessment research. Research in Developmental Disabilities, 32, 621-624.

Matson, J.L., Sipes, M., Horovitz, M., Worley, J.A., Shoemaker, M.E., \& Kozlowski, A.M. (2011b). Behaviors and corresponding functions addressed via functional assessment. Research in Developmental Disabilities, $32,625-629$.

McConkey, R., Morris, I., \& Purcell, M. (1999). Communications between staff and adults with intellectual disabilities in naturally occurring settings. $J$ Intellect Disabil Res, 43, 194-205.

McLean, J.E., McLean, L.K., Brady, N.C., \& Etter, R. (1991). Communication profiles of two types of gesture using nonverbal persons with severe to profound mental retardation. J Speech Hear Res, 34, 294-308.

McLean, L.K., Brady, N.C., \& McLean, J.E. (1996). Reported communication abilities of individuals with severe mental retardation. Am J Ment Retard, $100,580-589$.

McLean, L.K., Brady, N.C., McLean, J.E., \& Behrens, G.A. (1999). Communication forms and functions of children and adults with severe mental retardation in community and institutional settings. J Speech, Language $\mathcal{E}$ Hearing Res, $42,231-240$.

Merrill, E.C., \& Jackson, T.S. (1992a). Degree of associative relatedness and sentence processing by adolescents with and without mental retardation. Am J Ment Retard, 97, 173-185.

Merrill, E.C., \& Jackson, T.S. (1992b). Sentence processing by adolescents with and without mental retardation. Am J Ment Retard, 97, 342-350.

Merrill, E.C., \& Mar, H.H. (1987). Differences between mentally retarded and nonretarded persons' efficiency of auditory sentence processing. Am J Ment Defic, 91, 406-414.

Murray, C. \& Lopez, A. (1996). Global Burden of Disease. Geneva, Switzerland: Harvard University Press. 
Oetting, J.B., \& Rice, M.L. (1991). Influence of the social context on pragmatic skills of adults with mental retardation. Am J Ment Retard, 95, 435-443.

Ouellette-Kuntz, H. Understanding Health Disparities and Inequities Faced by Individuals with Intellectual Disabilities. J Applied Res in Intellect Disabil, $18,113-121$.

Pace, G.M., Ivancic, M.T., Edwards, G.L., Iwata, B.A., \& Page, T.J. (1985). Assessment of stimulus preference and reinforcer value with profoundly retarded individuals. J Appl Behav Anal, 18, 249-255.

Pulsifer, M.B. (1996). The neuropsychology of mental retardation. J Int Neuropsychol Soc, 2, 159-176.

Purcell, M., Morris, I., \& McConkey, R. (1999). Staff Perceptions of the Communicative Competence of Adult Persons with Intellectual Disabilities. Br J Devel Dis, 88, 16-25.

Roane, H.S., Vollmer, T.R., Ringdahl, J.E., \& Marcus, B.A. (1998). Evaluation of a brief stimulus preference assessment. J Appl Behav Anal, 31, 605-620.

Romaniuk, C., \& Miltenberger, R.G. (2001). The Influence of Preference and Choice of Activity on Problem Behavior. J Positive Behavior Interventions, 3, 152.

Romski, M.A., \& Sevick, R.A. (1994). Adult-directed communications of youth with mental retardation using the system for augmenting. Journal of Speech E Hearing Research, 37, 617.

Salmento, M.M., \& Bambara, M. (2000). Teaching staff members to provide choice opportunities for adults with multiple disabilities. Journal of Positive Behavior Interventions, 2, 12.

Schepis, M.M., \& Reid, D.H. (1995). Effects of a voice output communication aid on interactions between support personnel and an individual with multiple disabilities. J Appl Behav Anal, 28, 73-77.

Schlosser, R.W., Belfiore, P.J., Nigam, R., Blischak, D., \& Hetzroni, O. (1995). The effects of speech output technology in the learning of graphic symbols. $J$ Appl Behav Anal, 28, 537-549.

Sigelman, C.K., Budd, E.C., Spanhel, C.L., \& Schoenrock, C.J. When in Doubt, Say Yes: Acquiescence in Interviews with Mentally Retarded Persons. Ment Retard, 19, 53-58. 
Stancliffe, R.J., \& Abery, B.H. (1997). Longitudinal study of deinstitutionalization and the exercise of choice. Ment Retard, 35, 159-169.

Söderholm, S., Meinander, M., \& Alaranta, H. (2001). Augmentative and alternative communication methods in locked-in syndrome. Journal of Rehabilitation Medicine (Taylor \& Francis Ltd), 33, 235-239.

van der Gaag, A. (1989). Joint assessment of communication skills: formalising the role of the carer. The British Journal of Mental Subnormality, 35, 22-28.

van der Meer, L., Sigafoos, J., O’Reilly, M.F., \& Lancioni, G.E. (2011). Assessing preferences for AAC options in communication interventions for individuals with developmental disabilities: a review of the literature. Research in Developmental Disabilities, 32, 1422-1431.

Ward, R.L., Nichols, A.D., \& Freedman, R.I. (2010). Uncovering Health Care Inequalities among Adults with Intellectual and Developmental Disabilities. Health \& Social Work, 35, 280-290.

Ypsilanti, A., \& Grouios, G. (2008). Linguistic Profile of Individuals with Down Syndrome: Comparing the Linguistic Performance of Three Developmental Disorders. Child Neuropsychology, 14, 148-170.

\subsection{References (PD)}

Anonymous (2005), Empowering Marginal Communities with Information Networking (IGI Global).

Barak, Azy and Grohol, John M. (2011), 'Current and Future Trends in InternetSupported Mental Health Interventions', Journal of Technology in Human Services, 29 (3), 155-96.

Barak, Azy, et al. (2008), 'A Comprehensive Review and a Meta-Analysis of the Effectiveness of Internet-Based Psychotherapeutic Interventions', Journal of Technology in Human Services, 26 (2-4), 109-60.

Ben-Zeev, Dror, et al. (2012), 'Mobile Technologies Among People with Serious Mental Illness: Opportunities for Future Services', Administration and Policy in Mental Health and Mental Health Services Research, ePub ahead of print, 1-4. 
Bowers, Len, et al. (2009), Talking With Acutely Psychotic People: Communication skills for nurses and others spending time with people who are very mentally ill (London, England: City University).

Brockelman, Karin F. (2011), 'Faculty Members' Ratings of the Effectiveness of Academic Strategies for University Students with Psychiatric Disabilities', Journal of Postsecondary Education and Disability, 24 (1), 43-52.

Burda, Charon, et al. (2012), 'Medication adherence among homeless patients: A pilot study of cell phone effectiveness', Journal of the American Academy of Nurse Practitioners, ePub ahead of print: 26 Jun, DOI: 10.1111/j.17457599.2012.00756.x.

Byng, Richard and Jones, Roger. (2004), 'Mental Health Link: the development and formative evaluation of a complex intervention to improve shared care for patients with long-term mental illness'. Journal of Evaluation in Clinical Practice, 10 (1), 27-36.

Carolyn, Doughty and Tse, Samson (2005), 'The Effectiveness of Service UserRun or Service User-Led Mental Health Services for People with Mental Illness: A Systematic Literature Review', (Wellington, New Zealand: Mental Health Commission).

Chan, Kevin K. S. and Mak, Winnie W. S. (2012), 'Shared decision making in the recovery of people with schizophrenia: The role of metacognitive capacities in insight and pragmatic language use', Clinical Psychology Review, 32 (6), 535-44.

Cimo, Adriana, et al. (2012), 'Effective lifestyle interventions to improve type II diabetes self-management for those with schizophrenia or schizoaffective disorder: a systematic review', BMC Psychiatry, 12 (1), 24-24.

Cleary, Michelle, et al. (2008), 'Demystifying Research and Evidence-Based Practice for Consumers and Carers: Development and Evaluation of an Educational Package', Issues in Mental Health Nursing, 29 (2), 131-43.

Drake, R. E. and Latimer, E. (2012), 'Lessons learned in developing community mental health care in North America', World Psychiatry, 11 (1), 47-51.

Druss, Benjamin G., et al. (2010), 'The Health and Recovery Peer (HARP) Program: A Peer-Led Intervention to Improve Medical Self-Management for Persons with Serious Mental Illness', Schizophrenia research, 118 (1-3), 264-70. 
Efstathiou, G. (2009), 'Students' psychological web consulting: function and outcome evaluation', British Journal of Guidance \& Counselling, 37 (3), 243-55.

Elbogen, Eric B., et al. (2007), 'Competence to complete psychiatric advance directives: effects of facilitated decision making', Law and Human Behavior, 31 (3), 275-89.

Gainsbury, Sally and Blaszczynski, Alex (2011), 'A systematic review of Internetbased therapy for the treatment of addictions', Clinical Psychology Review, 31 (3), 490-98.

Garces, Juan Pablo Domecq, et al. (2012), 'Eliciting Patient Perspective in PatientCentered Outcomes Research: A Meta Narrative Systematic Review', (Rochester, MN: Patient-Centered Outcomes Research Institute, Mayo Clinic).

Garcia-Perez, Lidia and Serrano-Aguilar, Pedro 'Cost-Effectiveness of Interventions to Enhance Medication Adherence in Psychiatric Patients: A Systematic Review', Current Clinical Pharmacology, 6 (2), 115-24.

Hall, Elizabeth A., et al. (2003), 'Staying in Touch: A Fieldwork Manual of Tracking Procedures for Locating Substance Abusers in Follow-up Studies, 2nd edition', (UCLA Integrated Substance Abuse Programs).

Happell, Brenda (2008), 'Determining the effectiveness of mental health services from a consumer perspective: Part 2: Barriers to recovery and principles for evaluation', International Journal of Mental Health Nursing, 17 (2), 123-30.

Happell, Brenda, Scott, David, and Platania-Phung, Chris (2012), 'Provision of Preventive Services for Cancer and Infectious Diseases Among Individuals with Serious Mental Illness', Archives of Psychiatric Nursing, 26 (3), 192-201.

Howard, Matthew O., McMillen, Curtis J., and Pollio, David E. (2003), 'Teaching Evidence-Based Practice: Toward a New Paradigm for Social Work Education', Research on Social Work Practice, 13 (2), 234-59.

Huang, Yan-hua, et al. (2007), 'Factors Relating to Computer Use for People with Mental Illness', in Marvin Dainoff (ed.), Ergonomics and Health Aspects of Work with Computers (Lecture Notes in Computer Science, 4566: Springer Berlin / Heidelberg), 225-30. 
Ingoldsby, Erin M. (2010), 'Review of Interventions to Improve Family Engagement and Retention in Parent and Child Mental Health Programs', Journal of child and family studies, 19 (5), 629-45.

Jeste, Dilip V., et al. (2008), 'Multimedia educational aids for improving consumer knowledge about illness management and treatment decisions: A review of randomized controlled trials', Journal of Psychiatric Research, 42 (1), 1-21.

Kahn, Linda S., et al. (2009), 'Telephonic nurse case management for patients with diabetes and mental illnesses: a qualitative perspective', Chronic Illness, 5 (4), 257-67.

Kolbasovsky, A., Reich, L., and Meyerkopf, N. (2010), 'Reducing six-month inpatient psychiatric recidivism and costs through case management', Care Management Journals, 11 (1), 2-10.

Kreyenbuhl, Julie, Nossel, Ilana R., and Dixon, Lisa B. (2009), 'Disengagement From Mental Health Treatment Among Individuals With Schizophrenia and Strategies for Facilitating Connections to Care: A Review of the Literature', Schizophrenia Bulletin, 35 (4), 696-703.

Luciano, Mario, et al. (2012), 'A 'family affair'? The impact of family psychoeducational interventions on depression', Expert Review of Neurotherapeutics, 12 (1), 83-91.

Lysaker, Paul H., et al. (2010), 'Psychotherapy and recovery from schizophrenia: A review of potential applications and need for future study', Psychological Services, 7 (2), 75-91.

Lysaker, Paul H., et al. (2011a), 'Poor insight in schizophrenia: Links between different forms of metacognition with awareness of symptoms, treatment need, and consequences of illness', Comprehensive Psychiatry, 52 (3), 253-60.

Lysaker, Paul H., et al. (2011b). 'Addressing metacognitive capacity for self reflection in the psychotherapy for schizophrenia: A conceptual model of the key tasks and processes', Psychology and Psychotherapy: Theory, Research and Practice, 84, 58-69.

MacDonald-Wilson, Kim L., Rogers, E. Sally, and Massaro, Joseph (2003), 'Identifying relationships between functional limitations, job accommodations, and demographic characteristics of persons with psychiatric disabilities', Journal of Vocational Rehabilitation, 18, 15-24. 
Martin, J. and Oswin, F. (2012), 'Mental health, access and equity in higher education', Advances in Social Network, 11 (1), 48-66.

McKay, E. and Martin, J. (2012), 'Mental health and wellbeing: Converging HCI with human informatics in higher education', Issues in informing science and information technology, 7 (3), 39-351.

McKenzie, M., et al. (1999), 'Tracking and follow-up of marginalized populations: a review', J Health Care Poor Underserved, 10 (4), 409-29.

McLendon, Tara and Petr, Chris (2008), 'Best Practices to Engage Parents of Children Receiving Mental Health Services'. Report \#22. Lawrence, KS: University of Kansas School of Social Work.

Menon, G., \& Miller-Cribbs, J. (2002). Online social work practice: Issues and guidelines for the profession. Advances in Social Work, 3(2), 104-116.

Mockford, Carole, et al. (2012), 'The impact of patient and public involvement on UK NHS health care: a systematic review', International Journal for Quality in Health Care, 24 (1), 28-38.

Nsiah-Kumi, P. A. (2008), 'Communicating effectively with vulnerable populations during water contamination events', J Water Health, 6 Suppl 1, 63-75.

Patel, Sapana R., Bakken, Suzanne, and Ruland, Cornelia (2008), 'Recent Advances in Shared Decision Making for Mental Health', Current opinion in psychiatry, 21 (6), 606-12.

Patterson, Thomas L. and Leeuwenkamp, Oscar R. (2008), 'Adjunctive psychosocial therapies for the treatment of schizophrenia', Schizophrenia Research, 100 (1-3), 108-19.

Petr, Christopher G., ed. (2008), Multidimensional Evidence-based Practice: Synthesizing Knowledge, Research and Values. NY: Routledge.

Pitkänen, Anneli, et al. (2012), 'Patient education methods to support quality of life and functional ability among patients with schizophrenia: a randomised clinical trial', (2), 247-56.

Rahman, Hakikur, ed. (2006), 'Empowering Marginal Communities with Information Networking. Hershey, PA: Idea Group Publishing. 
Robert, Glenn, et al. (2003), 'Redesigning mental health services: lessons on user involvement from the Mental Health Collaborative', Health Expectations, 6 (1), 60-71.

Roberts, David L. and Velligan, Dawn I. (2011), 'Medication adherence in schizophrenia', Drug Discovery Today: Therapeutic Strategies, 8 (1-2), 11-15.

Rosenberg, S. D. (2001), 'Developing Effective Treatments for Posttraumatic Disorders Among People With Severe Mental Illness', Psychiatric Services, 52 (11), 1453-61.

Rowe, J. (2012), 'Great expectations: a systematic review of the literature on the role of family carers in severe mental illness, and their relationships and engagement with professionals', Journal of Psychiatric and Mental Health Nursing, 19 (1), 70-82.

Scheyett, Anna (2008), 'Psychiatric Advance Directives: Benefits and Barriers', Current Psychiatry Reviews, 4 (3), 137-44.

Schmidt, Lisa and Monaghan, James (2012), 'Intensive Family Support Services: A Consultative Model of Education and Support', American Journal of Psychiatric Rehabilitation, 15 (1), 26-43.

Sims, Hannah (2012), 'Text Message Reminders of Appointments: A Pilot Intervention at Four Community Mental Health Clinics in London', Psychiatric Services, 63 (2), 161-61.

Spaniol, LeRoy (2001), 'Recovery from Psychiatric Disability: Implications for Rehabilitation Counseling Education', (15; Rehabilitation Education), 16775 .

Srebnik, Debra and Brodoff, Lisa (2003), 'Implementing Psychiatric Advance Directives: Service Provider Issues and Answers', Journal of Behavioral Health Services \& Research, 30 (3), 253-53.

Srebnik, Debra, Appelbaum, Paul S., and Russo, Joan (2004), 'Assessing competence to complete psychiatric advance directives with the competence assessment tool for psychiatric advance directives', Comprehensive Psychiatry, 45 (4), 239-45.

Srebnik, Debra S. and Kim, Scott Y. (2006), 'Competency for Creation, Use, and Revocation of Psychiatric Advance Directives', Journal of the American Academy of Psychiatry and the Law Online, 34 (4), 501-10. 
Steffen, S., et al. (2009), 'Discharge planning in mental health care: a systematic review of the recent literature', Acta Psychiatrica Scandinavica, 120 (1), 1-9.

Stjernswärd, Sigrid (2009), 'Designing online support for families living with depression', (Malmö, Sweden: Malmö University, Faculty of Health and Society).

Syrett, Michel (2011), 'Service user involvement in mental health research: a user's perspective', Advances in Psychiatric Treatment, 17 (3), 201-05.

Tait, Lynda and Lester, Helen (2005), 'Encouraging user involvement in mental health services', Advances in Psychiatric Treatment, 11 (3), 168-75.

Valimaki, Maritta, et al. (2008), 'Design and development process of patientcentered computer-based support system for patients with schizophrenia spectrum psychosis', Informatics for Health $\mathcal{E}$ Social Care, 33 (2), 113-23.

Van Dorn, Richard A., et al. (2008), 'Reducing barriers to completing psychiatric advance directives', Administration and Policy in Mental Health, 35 (6), 44048.

Van Metre, L., et al. (2011), 'Educating for wellness: a wellness education group intervention for adults with chronic severe mental illness living in the community', Issues Ment Health Nurs, 32 (7), 408-15.

Wilkinson, Anne, Wenger, Neil, and Shugarman, Lisa (2007), 'Literature Review on Advanced Directives', Washington, DC: US Department of Health and Human Services.

Wingood, Gina M. and DiClemente, Ralph J. (2008), 'The ADAPT-ITT Model', JAIDS Journal of Acquired Immune Deficiency Syndromes, 47 (Supplement 1), S40-S46-S40-S46.

Zygmunt, A. (2002), 'Interventions to Improve Medication Adherence in Schizophrenia', American Journal of Psychiatry, 159 (10), 1653-64. 